\title{
MICROCONTROLLER BASED ADAPTIVE IRRIGATION SYSTEM USING WSN FOR VARIETY CROPS AND DEVELOPMENT OF INSECT AVOIDANCE SYSTEM FOR BETTER YIELD
}

\author{
Patil Kalika Milind ${ }^{1}$, P.C. Bhaskar ${ }^{2}$ \\ ${ }^{1}$ Mtech Student, Electronics Engineering, Department of Technology, Shivaji, University, Maharashtra, India \\ ${ }^{2}$ Professor, Electronics Engineering, Department of Technology, Shivaji University, Maharashtra, India
}

\begin{abstract}
Agriculture is main source of livelihood of people. It provides food as well as large employment. So modernization of agriculture is important because traditional framing is unable to boost up the crop yield. Therefore farmer start to utilize the various technology to achieve better yield and reduce the required man power. Water is a precious natural resource, a basic human need and a prime national asset. Rapid development of human civilization and advances of scientific and technological innovations are changing the condition of life on earth, giving rise to basic transformations of environment. In India, the growth of population is about $2 \%$ per year. It is essential that food production should increase about $2.5 \%$ per year to provide a better food intake. The available water resources are to be optimally connected and beneficially utilized with appropriate priorities of use. Therefore The real time values of soil moisture, air humidity, temperature and water level in the soil are wirelessly transmitted using wireless technology. At the same time, the pest and diseases have increased and insects are responsible for major kinds of damage to growing crops. It directs injury to the plant, which eats leaves or fruit, or roots. Most vegetable crops are subject to pest damage. So protection from insect attack to the crop is essential for better production.
\end{abstract}

Keywords: Wireless Network, Soil Water Sensor, Insect Attack, Agricultural, Injury. $* * *$

\section{INTRODUCTION}

The system in [1] proposes Remote Monitoring and control Systems based on GSM. GSM network is a medium for transmitting the remote signal and communication takes place between monitoring centre and remote monitoring station. The central monitoring station performs real time control, alarm and data processing and also manages database. Receiving and sending of the data in the central monitoring station is achieved by using the GSM wireless communications module TC35 in [13] [4] introduced GPRS technology with better application prospect. The sensor node gathers the hydro graphic information such as water-level, gate position and rainfall. The sink node receives the realtime data; the information centre stores and processes those data which are transmitted from the sink node through the GPRS network

The competing demands for water are for irrigation, industrial production, domestic water supply, hydro power generation and environmental management. Increasing population and improved standards of living are increasing the demand for agricultural production. Irrigation water is supplied to supplement the water available from rainfall and the soil moisture in the crop root zone and the contribution to soil moisture from groundwater. But in many areas the amount and timing of rainfall are not sufficient to meet the moisture requirement of crops and irrigation is essential to raise crops necessary to meet the needs of food for the growing population.
A Low cost soil moisture monitoring system is explained in [5]. The paper describes a PC controlled irrigation monitoring and controlling system with wireless communication. The design of the overall system is based on the system must provide regular soil moisture measurements at low cost; the system must interface with an irrigation system to allow for automatic watering of the soil; and the measurement units must be discreet to everybody activity

Today a major Challenge is to introduce budget in agricultural and industrial water use. Major areas of water in canal irrigation are under utilization of night supplies, canal flow going waste in non-demand seasons due to lack of crop variation and absence of storage tanks within the system, improper canal water releases, unnecessary outflow losses in water transportation system and unscientific irrigation methods. Transportation losses are often high in urban water supply system due to leaking pipelines, resulting from corrosion and faulty pipe joints.

In [7], a wireless sensor network (WSN) is used for a temperature measurement system. In the system, temperature signals are acquired by digital multipoint thermometers, and transmitted to the advanced RISC microprocessor (ARM) by using Wireless Fidelity (Wi-Fi) technology. A special data storage file system is able for reading and writing Wireless sensor networks in home are easy to coverage

India has a diverse climate, a variety of weather conditions and a monsoon dominated rainfall pattern. The varying 
climatic conditions of India result in variety in agriculture. The distribution of crops and their productivity are depends upon climatic factors, soil and land topography.

The primary objective of irrigation is to increase agricultural productions on a continuous basis. Plants vary in their requirements for water and flexibility to environment. Irrigation systems are planned to meet the water requirement of crops under a cropping pattern. Crop water requirements can be met from rainfall, from the soil moisture in crop root zone by pumping groundwater from the area and through supplies from a irrigation system. The efficiency of water depends on type of soil, crop and its stages of growth. Land grading is also importance for irrigation. When an uneven land is irrigated, the high spots are watered too little and the low spots too much. This results in uneven crop growth, reduced yields and loss of water and fertilizers.

There are a number of studies which says that Wireless sensor networks are a cost effective solution for collecting, receiving and transmitting data. A RF based Weather monitoring System is proposed in [8]. It describes about measuring pressure, temperature and humidity in the atmosphere for up to date weather monitoring-Weather is monitored at different levels of the atmosphere, by using a hydrogen balloon in which pressure, temperature and humidity sensors are embedded. [9] Proposed PIC microcontroller based instrumentation is developed for measuring the changes of linear micrometer that represents the stem diameter changes [10]. Described the development of an embedded device which can control up to 8 devices by sending a specific SMS message from a cell-phone. This controller is extremely handy at places for controlling the $\mathrm{ON}$ and OFF switching of the device.

Modern irrigation equipment and technology like sprinkler, micro-sprinkler and drip systems have the capability of applying the desired quantity of water with high precision and uniformity. Also there is saving in the use of water as compared to surface irrigation. Drip irrigation is an efficient irrigation method .In this system water is applied frequently at low rates directly to the land surface close to the plant where the roots grow. Major advantages of drip irrigation is higher crop yields, improved quality of the harvested produce of the crop, savings in irrigation water, increased efficiency in fertilizer use, reduced energy consumption, tolerance to windy atmospheric conditions, reduced labour costs ,improved disease and pest control.

\section{PROPOSED SYSTEM}

The main approach of proposed system is to measure the soil water content present in soil and irrigate the water at particular crop as per its water requirement at different stages as well as protect the crops from insect attack using insect reppeller for better yield.

The above mentioned objectives can be achieved by implementing the system using PIC 16F877a at the field area. This unit can communicate with remote PC via Zigbee module interfacing. Soil moisture sensor, Humidity sensor and Temperature sensor can be interfaced with PIC16F877a which has inbuilt $\mathrm{ADC}$, and the data can be sent to $\mathrm{PC}$ serially via RF Zig bee module..

Figure 1 shows the schematic architecture of proposed system The microcontroller can be programmed for different types of crops with respect to their watering requirements as per FAO standards. When particular crop is selected by using MATLAB code with microcontroller, it will monitor soil water content as per crop growth stages indicated by FAO as well as monitor all required parameter like temperature and humidity.

It will control the watering valves as and when required via driver circuits. For controlling insects attack we can use primary mosquito repeller circuit to demonstrate the insects control mechanism.

At the PC side MATLAB based software can be implemented which will receive the data sent from field module via zigbee interface.Figure2 shows the hardware architecture of proposed system

The proposed system provides uniform and required level of water for both plain and sloppy areas and it avoids the water overflow at the sloppy areas and Provide protection from the insect attack to avoid crop damages

Water requirement of crops varies with the stage of its growth Water requirement is a 'demand' and the 'supply' would consist of contributions from any of the sources of water, the major source being the irrigation water (IR), effective rainfall(ER) and soil profile contributions $(\mathrm{S})$. Therefore water requirement is given as $\mathrm{WR}=\mathrm{IR}+\mathrm{ER}+\mathrm{S}$

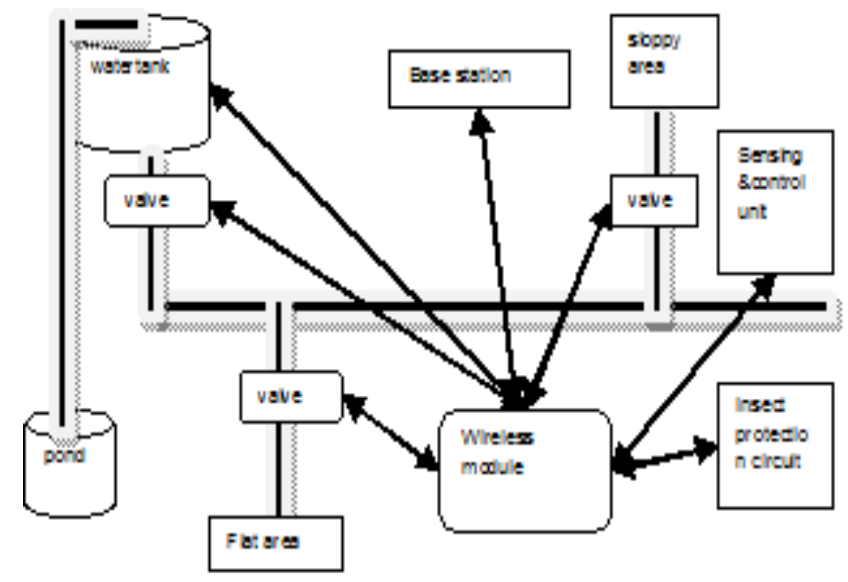

Fig1.SchematicDiagram for Proposed system 


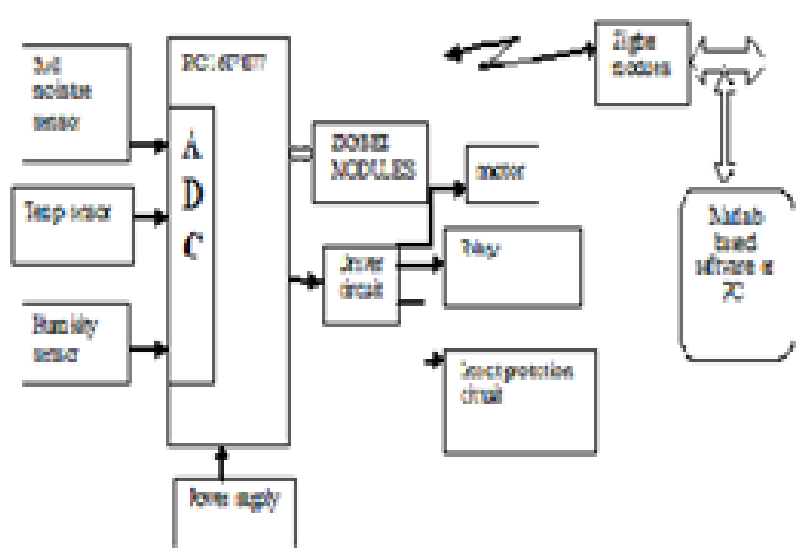

Fig2.Hardware Architecture of proposed system Field station Base station

In manually control irrigation systems, the motor has pulled out the water and irrigate the plant. But availability of water in the soil is not checked. So the wireless system to be monitor the condition of plant and if there is insufficient amount of water then system will check the plant status and water present in soil and then gives the water as per water requirement of that particular crop. So they can make efficient management, reduce labour and input expenses, increase yield .For that purpose automated sensing system will be most appropriate.

Insect have a direct impact on Agricultural food production by chewing the leaves of crop plants, sucking out plant juices, boring within the roots or leaves and spreading plant pathogen. Insects are responsible for two major kinds of damage to growing crops. First is direct injury done to the plant by the feeding insect, which eats leaves, fruit or root. The second type is indirect damage in which the insect itself does little or no harm but transmits a bacterial, viral or fungal infection into a crop. So protection from insect is essential for better yield.

\section{HARDWAREIMPLIMENTATION}

This system consists of moisture level sensors, PIC microcontroller, relays and insect avoidance kit. Figure 3 shows the circuit diagram of proposed system, At the field station, the sensors which are buried inside the soil send the signal to the microcontroller. The microcontroller converts the analog signal to digital values. This value is compared with a value representing the minimum allowable value below this minimum value, a signal is sent to turn on the corresponding Relay to allow water flow into the farm and vice-varsa. This is helpful to carried out the irrigation whenever required as well as to save energy and well crops health. Every procedure in scheduling is controlled by the program inside the microcontroller

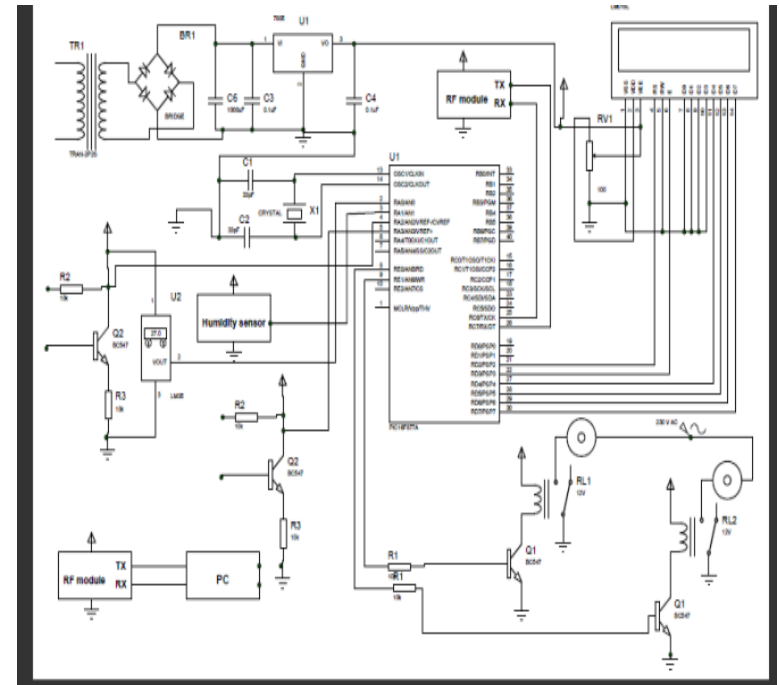

Fig3. Circuit diagram of Proposed system

Figure 4 shows the hardware of proposed system

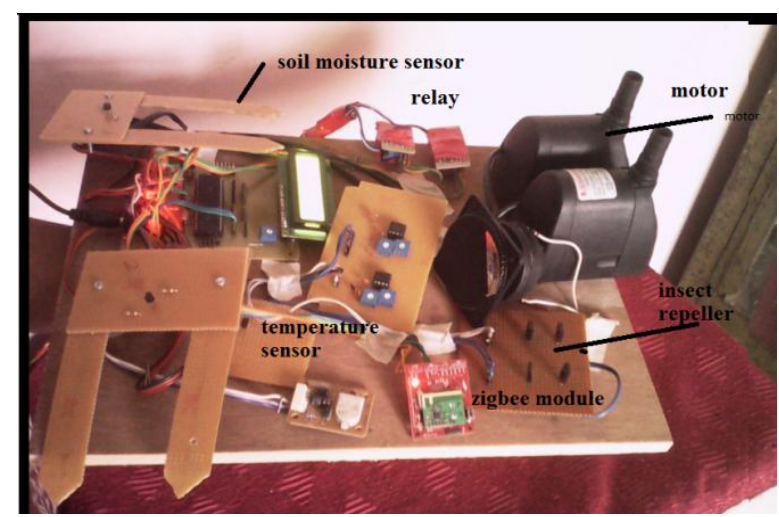

Fig 4.Hardware of proposed system

\subsection{At Field Station}

Figure 5 shows the hardware module for field station .In field station number of sensors are connected like temperature, soil moisture, humidity sensor. They send the signal viz zigbee module to the base station

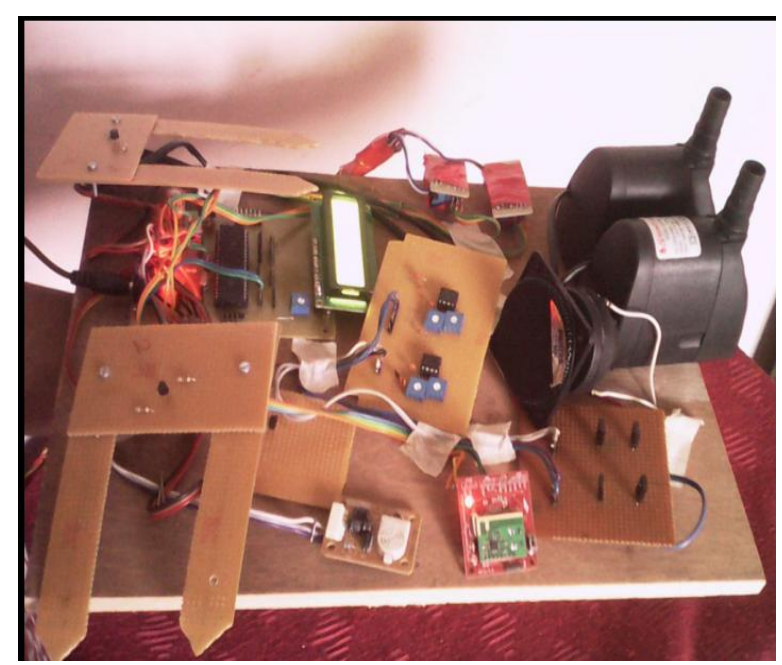

Fig 5.Hardware at Field station 


\subsection{Hardware at Base Station}

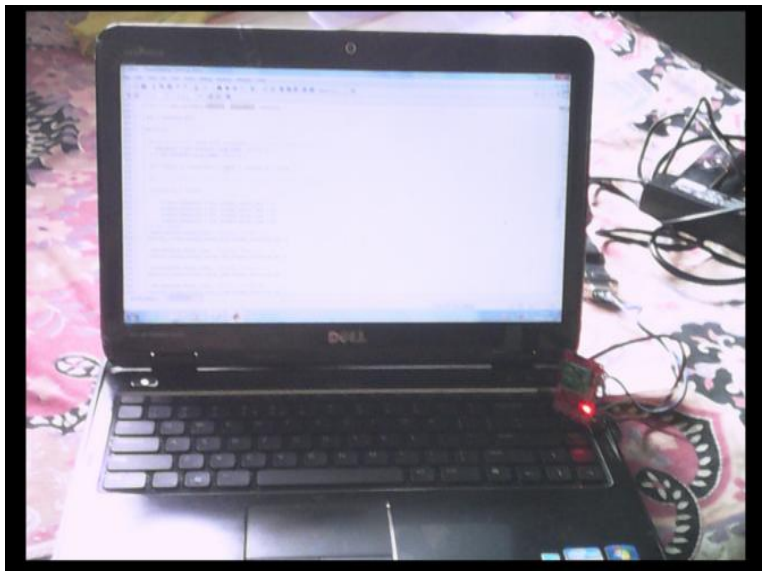

Fig 6 .Hardware at base station

The base station which receives the information data from the field station using wireless module and check the predefined condition. On the basis of that base station send the control signal back to the field station. Also display the sensor reading on LCD display. Figure 6 shows hardware at base station

\subsection{Hardware for Insect Avoidance}

Managing the ecosystem on an farm is very challenging and more complex when factoring in insect and disease pests. No single method is likely to be adequate for them .In this system we can use a insect reppeller for insect avoidance. Figure 7 shows the insect repeller circuit.This is controlled by microcontroller,

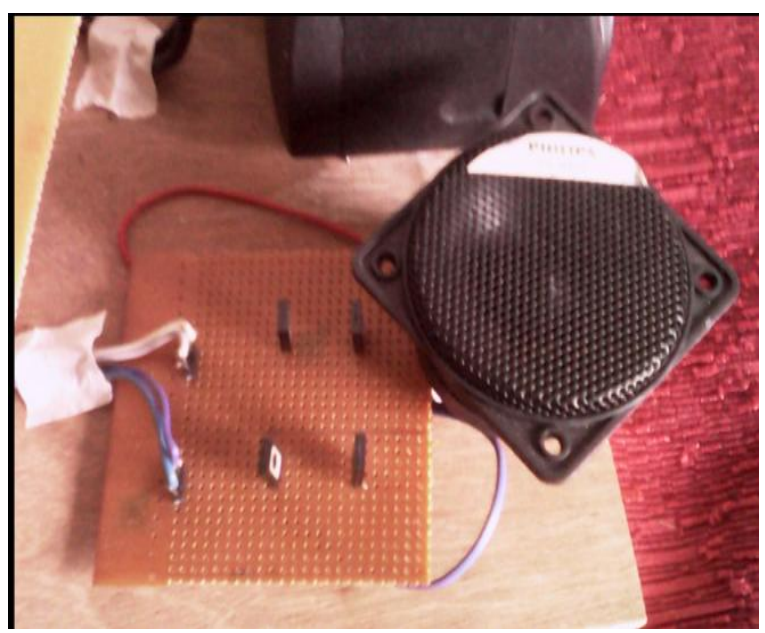

Fig7. Hardware of Insect repeller circuit

\section{SOFTWARE IMPLEMENTATION}

The field station send the signal to the base station viz. Zigbee wireless module. At the base station using MATLAB we can write a code for a particular crop and observe the result. Figure shows a MATLAB code for a selected crop. Figure 8 shows the result for the same code. Figure 9 shows the result window at base station.

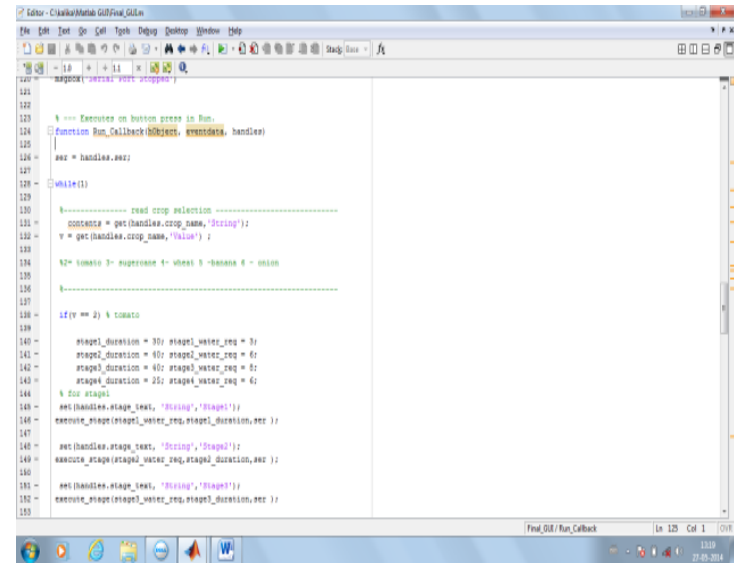

Fig 8.Snapshot of MATLAB code to observe field station signal at base workstation

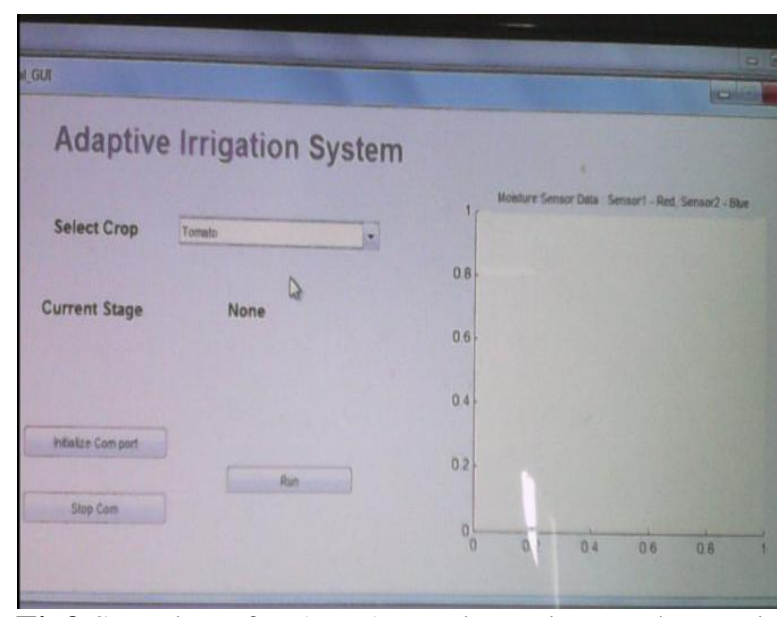

Fig9.Snapshot of MATLAB code to observe the result

\section{RESULTS}

$>\quad$ By using PIC microcontroller we can automatically run the system

$>\quad$ At field station the soil moisture sensor can sense the soil moisture and send to the microcontroller

$>\quad$ This signal is analoghence ADC converts it into a digital signal and send it to the base station using zigbee module

$>\quad$ At the base station the received signal is compared with the threshold value by using MATLAB.

$>\quad$ At base station MATLAB code defines different crops water requirement depending upon their growing stages required for proper irrigation.

$>\quad$ At the same time temperature and humidity are observed

The insect avoidance circuit is used to avoid insect attack.

$>$ Figure 10 shows the output of soil moisture sensor at base station 


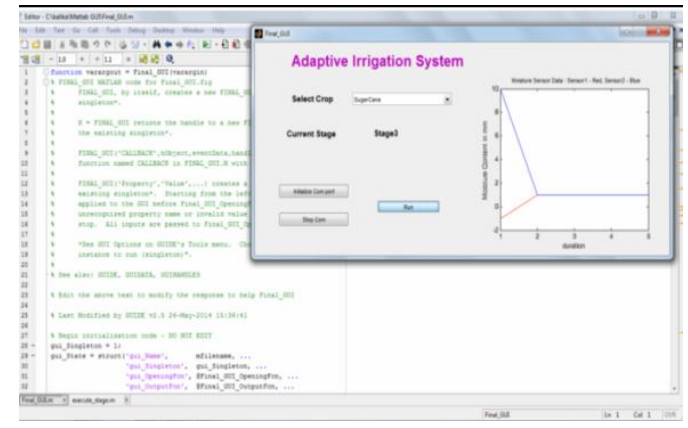

Figure10.Snapshot of output of soil moisture sensor at base station

\section{CONCLUSIONS}

This system is relatively low cost and user friendly due to a zigBee network used. This system provides automated irrigation for different crops along with water requirement for those crops at different growing stages using MATLAB. Also, the system is incorporated with insect repeller to avoid insects for better yield.

\section{REFERENCES}

[1]. G. K. Banerjee, Rahul Singhal, Bhubaneswar, Orissa India "Micro controller Based Poly house Automation Controller", International Symposium on Electronic System Design, pp.158-162, Dec 2010.

[2]. Bhutada, S.; Shetty, S.; Malye, R.; Sharma, V.; Menon, S.;Rama moorthy, R, "Implementation of a fully automated green house using SCADA tool like LabVIEW",International conference on Advanced Intelligent Mechatronics. Proceedings, pp. 741-746, 2005

[3]. Wenbin Huang, Guanglong Wang, Jianglei Lu, FengqiGao, Jianhui Chen "Research of wireless sensor networks for an intelligent measurement system based on ARM", International conference on Mechatronics and Automation Conference on, pp. 1074 - 1079, 2011.

[4]. Healy, M. Newe, T. Lewis "Wireless Sensor Node hardware: A review", IEEE 15th International Symposium on Consumer Electronics, pp. 621-624, 2011.. [15] Ahmed, V. , " Innovative cost effective approach fro cell phone based remote controlled embedded system for irrigation", International Conference on Communication Systems and Network Technologies, 2011, pp. 419-144, 2011.

[5]. A.hmed, V., “'Innovative cost effective approach fro cell phone based remote controlled embedded system for irrigation", International Conference on Communication Systems and Network Technologies, 2011, pp. 419-144, 2011.

[6]. Vasif Ahmed and Siddharth A. Ladhake; "Design of ultra low cost cell phone based embedded system for irrigation"; IEEE Transactions on Consumer Electronics, 2010 , Vol. 55, No. 2 , pp. 718-721.

[7]. I.F. Akyildiz, W. Su, Y. Sankara subramaniam, E.Cayirci , "Wireless sensor networks: a survey", IEEE Transactions on Consumer Electronics, vol. 44, pp. 1291-1297, Aug 2002.

[8]. Mahir Dursun, SemihOzden; "A prototype of PC based control of irrigation" International conference on Environmental Engineering and Applications, vol. 50, pp. s255-258, Nov. 2010.
[9]. Ma Shuying, Ma Yuquan, Chen Lidong, Liu Shiguang, "Design of a new measurement and control system of CO2 for greenhouse based on fuzzy control", International Conference on Computer and Communication Technologies in agriculture engneering 2010, pp 128-131, May 2008

[10]. Automation, 2010, pp. 1012-1014

[11]. Yan Xijun, Lu limei, XuLizhong, "The Application of wireless sensor network in the Irrigation Area Automatic System", International Conference on Networks Security, Wireless Communications and Trusted Computing 2009, pp. 21-24.

[12]. "XBee-2.5-Manual," ZigBee RF communication protocol. (2008). Minnetonka: Digi International Inc.

[13]. XBee OEM RF Modules-ZigBee- v1.x1x [2007.06.01] (C) 2007 Digi International, Inc.www.digi.com

[14]. V. Ramya, B. Palaniappan, Boby George, "Embedded System for Automatic Irrigation of Cardamom Field using Xbee-PRO Technology", International Journal of Computer Applications (0975 - 8887) Volume 53- No.14, September 2012.

[15]. Allen, R.G.; Pereira, L.S.; Raes, D. and Smith,M. (1998)

[16]. "PANSY: a Portable Autonomous Irrigation System" by Benjamin Beckmann and Ajay Gupta Wireless Sensornet(WiSe) Laboratory Department of Computer Science Western Michigan University Kalamazoo, Michigan, 49008-5466, USA

[17]. "Wireless Irrigation Pump Safety System (WIPSS)" by Andy Norby, Doug Butler, Nick Butts

[18]. "Wireless control of irrigation system operating from zø induction motor fed by $1 \varnothing$ supply" by n. Sandeep and pranava moorthy b.,meenakshi sundararajan engineering college, chennai. 